\title{
The Threshold Effect of the Financial Structure Optimization and Economic Structure Transformation Dual-wheel Driving Based on Data from Guangdong-Hong Kong-Macao Greater Bay Area
}

\author{
Shizhong Xiong ${ }^{1, *}$ \\ ${ }^{1}$ Department of Accounting, Xinhua College of Sun Yat-Sen University, Dongguan, Guangdong, China \\ *Corresponding author. Email: xsz9293@126.com
}

\begin{abstract}
This paper selects the panel data of $\mathbf{1 1}$ cities in the Guangdong-Hong Kong-Macao Greater Bay Area from 1997 to 2017, and uses the empirical methods of Fully Modified Ordinary Least Squares and Granger to analyze the dynamic relationship between economic structure transformation, financial structure and economic growth in the Greater Bay Area. It proves through test that the economic structure transformation and financial structure optimization have become the support mode of the "dual-wheel driving" for economic growth, but there may be a certain degree of "threshold effect". In view of this situation, it puts forward relevant policy suggestions to build a long-term coordinated development mechanism, which is conducive to the high-quality economic development of the Greater Bay Area.
\end{abstract}

Keywords: financial structure optimization, economic structure transformation, economic growth, threshold effect

\section{INTRODUCTION}

The 19th National Congress of the CPC and the Fifth Plenary Session of the 19th Central Committee of the CPC clearly pointed out that China's economy has entered a new normal, where the transformation of the contradiction focuses on the optimization of the structure and efficiency, and the efforts on the transformation of the economic structure and the optimization of the financial structure has become the top priority of the sustainable and high-quality economic development. And this is also true of the economic development in the Greater Bay Area. The higher the quality of economic development is, the stronger the real economy and the stronger the foundation of comprehensive national strength will be. Without the long-term growth and development of the real economy, it is impossible for the economy and society to develop healthily, continuously and comprehensively. The optimization of financial structure, the transformation of economic structure and the growth of real economy are closely related. The real economy is the foundation for the structural

*This paper is the phased research results of the project approved by the Department of Finance of Guangdong Province (Project No.: Z201951). transformation of the optimized financial structure. Without the sound, sustained and all-round growth of the real economy, the optimization of the financial structure and the structural transformation of the economy will lack a strong economic support. The optimization of financial structure and the transformation of economic structure are two wheels driving the growth of real economy. Without the effective coupling of the two, real economic growth will become water without a source. Therefore, a systematic study on the relationship between financial structure optimization, economic structure transformation and real economy growth in the Guangdong-Hong Kong-Macao Greater Bay Area not only has important theoretical value for the construction of the Greater Bay Area, but also has great practical significance in promoting high-quality economic development.

\section{LITERATURE REVIEW}

\section{A. Transformation of financial structure and economic growth}

After Goldsmith put forward the theory of financial structure, Levine et al. revised and supplemented the research on the relationship between financial 
development and economic growth, and developed the theory of financial structure development, confirming the non-neutral effect of financial structure on real economy.

\section{B. Economic structure and financial structure}

Since the 21 st century, both Chinese and foreign scholars have attached importance to the relationship between economic structure and financial structure. They argue that economic structure decides the financial structure and financial structure has adverse effect to the economic structure. They have made empirical analysis and research on promoting the optimization of economic structure through the optimization of financial structure, put forward the theory of optimal financial structure, and drew the conclusion that there is a long-term and short-term relationship between the economic structure, the financial structure and the industrial structure, and there is a benign interaction between economic structure and financial structure, presenting a single causal relationship.

\section{Factors affecting the real economy}

The research of Cochrane, Jacobson, Franklin, Stephan, Terhi, Giampaolo, Lorenzo and Daryna et al. showed that financial market and its stability, market rate of return, inflation, financial crisis, financial structure and other elements interact with and influence economic growth, and the characteristics of real economy determine the change and optimization of financial format.

To sum up, through the combing and analysis of the economic growth, economic structure adjustment and the deepening of financial institutions to different documents, it can be concluded that there are more research on the local relationships of the three yet less holistic approach; the theoretical framework of the system has not been formed and a systematic study of financial industry structure and there is a lack of systematic research on the effects of financial structure, economic structure transformation and their coupling on real economy growth; and the empirical research is in its infancy.

\section{RESEARCH DESIGN}

A. The framework of economic growth, economic structure and financial structure is constructed and the hypothesis and econometric models are proposed

1) The framework of economic growth, economic structure and financial structure: Based on the neoclassical economic growth theory and incorporating financial and economic structural factors, the model evolves into:

$$
\begin{aligned}
\mathrm{Y} & =\sum Y_{t}(A K L) \cdot \sum Y_{t}(F) \\
& =\alpha \mathrm{ES}+\beta \mathrm{FS}
\end{aligned}
$$

In this formula, $\sum Y_{t}(A K L)$ is the economic structure (ES), and $\sum Y_{t}(F)$ is the financial structure (FS).

The driving force for economic growth is to mobilize economic structure optimization is stable economic growth, while the driving force for economic structure to promote economic growth in turn is the optimization of economic structure.

The support for the optimization of financial structure driven by economic growth is risk management. Under the new economy, finance and science and technology are faced with greater uncertainty, namely risk, which amplifies the demand for financial risk management. In turn, the core driving force for economic growth driven by the optimization of financial structure is to improve the risk management level of economic operation and form the industrial agglomeration of resources and elements under the guidance of interests.

2) Research condition assumption: Based on the above basic theoretical framework, the following condition assumptions are made:

- Condition assumes 1: economic structural adjustment and economic growth present positive correlation.

- Condition assumption 2: the optimization of financial structure contributes to economic development and growth.

- Condition hypothesis 3: there is coupling effect between the interaction terms of economic and financial structure (positive or negative).

3) Econometric model construction: The core of the threshold effect of the financial structure optimization and economic structure transformation dual-wheel driving is the coupling of economic structure and financial structure. To this end, the following econometric models are constructed:

$$
\begin{aligned}
& G_{y}=\alpha+\beta_{1} \mathrm{ES}+\beta_{2} \mathrm{FS}+\mu \\
& G_{y}=\alpha+\beta_{1} \mathrm{ES}+\beta_{2} \mathrm{FS}+\beta_{3} \mathrm{ES} * \mathrm{FS}+\mu
\end{aligned}
$$

In the models, $G_{y}$ presents economic growth, ES presents economic structure, FS presents financial structure and ES $\%$ FS refers to the coupling effect between economic structure and financial structure. 


\section{B. Research method}

By use of the method of Group Mean Panel FMOLS, through empirical research, this paper analyzes the dynamic relationship between economic structure transformation, financial structure and economic growth in the Greater Bay Area, and uses the Granger-causality to test the dynamic mechanism of economic structure transformation and financial structure optimization as two-wheel drive of economic growth, and finds that there may be threshold effect to some extent.

\section{Data sources and description variables}

The data are from the wind database and the China Statistical Yearbook. In this paper, nine cities in the Pearl River Delta (Guangzhou, Shenzhen, Zhuhai, Foshan, Dongguan, Zhongshan, Jiangmen, Huizhou and Zhaoqing) in the Guangdong-Hong Kong-Macao
Greater Bay Area and two special zones of Hong Kong and Macao are selected as the research objects. The explained variable is expressed by the logarithm of GDP per capita, and the economic structure is expressed by the proportion of the tertiary industry in GDP; financial structure is expressed through the ratio of stock market value to total financial assets.

\section{THE "DUAL-WHEEL DRIVING EFFECT" OF ECONOMIC STRUCTURE AND FINANCIAL STRUCTURE}

\section{A. Unit root test}

Considering the heterogeneity of panel data in countries and regions, ADF and other methods are used to make the verification and the results are shown as follows ("Table I").

TABLE I. UNIT ROOT TEST

\begin{tabular}{|l|l|l|l|l|l|}
\hline & \multicolumn{1}{|c|}{ LLC } & \multicolumn{1}{c|}{ Breitung } & \multicolumn{1}{c|}{ IPS } & \multicolumn{1}{c|}{ ADF } & \multicolumn{1}{c|}{ PP } \\
\hline$G_{y}$ & 0.412 & 2.348 & -0.561 & 18.436 & 42.456 \\
\hline$\Delta G_{y}$ & $-4.435^{* * *}$ & $-1.421^{*}$ & $-2.601 * * *$ & $36.821 * * *$ & $43.571 * * *$ \\
\hline ES & -0.471 & 0.837 & 0.536 & 20.076 & 20.136 \\
\hline$\Delta E S$ & $-9.135 * * *$ & $-5.235^{* * *}$ & $-7.038^{* * *}$ & $68.485 * * *$ & $91.085 * * *$ \\
\hline FS & 23.687 & -1.286 & 0.351 & 10.149 & $41.131 * * *$ \\
\hline$\Delta F S$ & $-9.457 * * *$ & $-6.721 * * *$ & $-8.156^{* * *}$ & $81.439 * * *$ & $183.643 * * *$ \\
\hline
\end{tabular}

a. Note: $: \Delta$ represents the first order difference of the variable; $\$$ and $*$ represent the significance level of $1 \%, 5 \%$ and $10 \%$ respectively.

The results show that, after the difference treatment, the variables are integrals of the same order, so there may be co-integration relationships between the linear combinations.

With Kao test as the reference standard, Pedroni (1997) was used to conduct $\mathrm{T}$ and $\mathrm{P}$ value test. The results are shown in "Table II".

The results show that the five statistical variables support the original hypothesis conditions. The relationship between panel and inter-group statistics of ADF showed a significant level; through the cointegration equation, the coefficients of independent variables are analyzed to compare the effects of economic structure and financial structure variables in different regions on economic growth.
TABLE II. RESULTS OF CO-INTEGRATION TEST

\begin{tabular}{|c|c|c|c|}
\hline Method & $\begin{array}{c}\text { Statistical } \\
\text { magnitude }\end{array}$ & $\mathbf{T}$ & $\mathbf{P}$ \\
\hline \multirow{7}{*}{ Pedroni } & Panel v & $7.862 * * *$ & 0.0000 \\
\hline & Panel rho & -0.126 & 0.562 \\
\hline & Panel pp & $-1.3 .1 * * *$ & 0.0000 \\
\hline & Panel ADF & $-1.601 * * *$ & 0.0000 \\
\hline & Group rho & -1.742 & 0.994 \\
\hline & Group pp & $-1.407 *$ & 0.106 \\
\hline & Group ADF & $-1.698 * * *$ & 0.0062 \\
\hline \multirow{3}{*}{ Kao } & $\mathrm{ADF}$ & $-1.607 * * *$ & 0.043 \\
\hline & Residual variance & 0.020 & \\
\hline & HAC variance & 0.029 & \\
\hline
\end{tabular}

\section{B. Regression analysis}

FMOLS method of inter-group mean panel was selected for measurement regression, and the results are shown in "Table III".

TABLE III. REGRESSION RESULT

\begin{tabular}{|c|c|c|c|c|}
\hline Variables & Model 1 & Model 2 & Model 3 & Model 4 \\
\hline ES & $0.095 * * *$ & $0.152 * * *$ & $0.102 * * *$ & $0.132^{* * * *}$ \\
\hline FS & $0.412 * * *$ & $0.632^{* * * *}$ & $0.632 * * *$ & $0.692 * *$ \\
\hline ES $\approx S$ & & $-0.007 * * *$ & $0.007 * * *$ & $-0.018^{*}$ \\
\hline
\end{tabular}


The results of Model 1 show that the independent variables are statistically significant at the level of $1 \%$. This fully proves that economic growth comes from the adjustment of economic structure and the optimization of financial structure, so as to verify the validity of hypothesis 1 and 2.

Model 2 shows that, due to the differentiation between the economic structure and financial structure of the Guangdong-Hong Kong-Macao Greater Bay Area, considering after ES $\%$ FS the cross phase coefficient is negative and is very significant at the $1 \%$ level, economic structure is negatively correlated with financial structure, that is, the coupling effect is negative.

Model 3 and 4 are obtained by regression of high and low income groups after considering the per capita income in 2017. Model 3 shows that the cross-phase coefficient of economic structure and financial structure of high and low income group is positive and significant at the level of $1 \%$. This shows that the mutual coupling between economic structure and financial structure brings about the "dual- wheel driving" for economic growth, realizing high-quality economic development and growth. Model 4 shows that the cross-phase coefficient of economic structure and financial structure of the low-income group is negative and significant at the level of $10 \%$. This indicates that the coupling effect between economic structure and financial structure brings about a "two-wheel drive" for economic growth, and the high-quality economic development and growth are inhibited, that is, there is a certain degree of "threshold effect".

\section{V. "THRESHOLD EFFECT" OF THE DUAL- WHEEL DRIVING}

\section{A. Unit root test}

It can be seen from the above analysis that, on the whole, the transformation of economic structure and the optimization of financial structure are conducive to high-quality economic development and growth. However, due to regional income differences and their causes, unit root verification ("Table IV") and Granger causality test ("Table V") need to be carried out for the regions respectively.

TABLE IV. PARTITION UNIT ROOT TEST RESUlTS

\begin{tabular}{|c|c|c|c|c|c|c|c|c|c|}
\hline & \multicolumn{3}{|c|}{ Gy } & \multicolumn{3}{|c|}{ ES } & \multicolumn{3}{|c|}{ FS } \\
\hline & ADF & K,t,c & pp & ADF & $\mathbf{K}, \mathbf{t}, \mathbf{c}$ & $\mathbf{P p}$ & ADF & $\mathbf{K}, \mathbf{t}, \mathbf{c}$ & pp \\
\hline Hong Kong & -3.091 & $1,0,0$ & -1.120 & 0.352 & 1.0 .0 & 0.741 & -2.645 & 0.0 .0 & -2.645 \\
\hline Macao & -2.781 & 1.0 .0 & -0.912 & 0.438 & 1.0 .0 & 0.801 & -2.465 & 0.0 .0 & -2413 \\
\hline Pearl River Delta & 2.346 & 1.0 .0 & 7.087 & 4.012 & 0.0 .0 & 3.878 & -1.201 & 0.0 .0 & -1.010 \\
\hline China & 1.623 & 1.0 .0 & 6.487 & 3.874 & 0.0 .0 & 3.276 & -1.327 & 0.0 .0 & -1.126 \\
\hline $\begin{array}{l}\text { First order } \\
\text { difference }\end{array}$ & & & & & & & & & \\
\hline Hong Kong & $-2.893 *$ & $1,0,0$ & $-4.693 * * *$ & $-3.527 *$ & 0.0 .0 & $-3.413^{*}$ & $-6.102 * * *$ & 0.0 .0 & $-9.793 * * *$ \\
\hline Macao & $-2.543^{*}$ & 1.0 .0 & $-4.343 * * *$ & $-3.243^{*}$ & 0.0 .0 & $-3.123^{*}$ & $-6.043^{* * *}$ & 0.0 .0 & $-9.123^{* * *}$ \\
\hline Pearl River Delta & $-3.687 * * *$ & 1.0 .0 & $-4.626 * * *$ & $-4.123 * * *$ & 0.0 .0 & $-4.203 * * *$ & $-6.193 * * *$ & 0.0 .0 & $-10.053^{* * * *}$ \\
\hline China & $-4.297 * * *$ & 1.0 .0 & $-5.138 * * *$ & $-5.293 * * *$ & 0.0 .0 & $-5.363 * * *$ & $-6.443 * * *$ & 0.0 .0 & $-10.693 * * *$ \\
\hline
\end{tabular}

Note: $=\bar{m}=$ and $\bar{x}$ represent significant levels of $1 \%, 5 \%$ and $10 \%$, respectively. $\mathrm{k}, \mathrm{t}$ and $\mathrm{c}$ respectively represent the lagging term, trend term and intercep

TABLE V. GRANGER CAUSALITY TEST OF ECONOMIC GROWTH AND ECONOMIC STRUCTURE

\begin{tabular}{|l|l|l|l|l|l|l|}
\hline \multirow{2}{*}{ Regions } & \multicolumn{3}{|c|}{ ES Gy } & \multicolumn{3}{c|}{ Gy $\$$ ES } \\
\cline { 2 - 7 } & \multicolumn{1}{|c|}{ F } & P & K & F & P & K \\
\hline Hong Kong & $4 . .83143^{* *}$ & 0.0464 & 2 & $4.79231^{* *}$ & 0.0297 & 2 \\
\hline Macao & $4.85003^{* *}$ & 0.0821 & 2 & $4.71043^{* *}$ & 0.0299 & 2 \\
\hline Pearl River Delta & 3.16824 & 0.1672 & 4 & $4.99104^{*} *$ & 0.0362 & 4 \\
\hline China & 2.66813 & 0.1405 & 4 & $4.98124 * *$ & 0.0334 & 4 \\
\hline
\end{tabular}

Note:***, ** and * represent significant levels of $1 \%, 5 \%$ and $10 \%$, respectively. $¥$ stands for "non-granger reason", and the lag period is 4

The results show that all variables support the unit root hypothesis, and after differential treatment, all variables are significant at the level of $10 \%$, and are first order integrals.

\section{B. Granger causality tests}

Through differential processing, all variables become stable sequences, from which the Granger causality between economic growth, economic structure and financial structure can be analyzed and tested one by one (see "Table VI"). 
It can be seen from the test results that all countries and regions support economic growth as the Granger cause of economic structural adjustment, indicating that economic structural adjustment is the result of economic growth.

TABLE VI. GRANGER CAUSALITY TEST OF ECONOMIC GROWTH AND FINANCIAL STRUCTURE

\begin{tabular}{|l|l|l|l|l|l|l|}
\hline \multirow{2}{*}{ Regions } & \multicolumn{3}{|c|}{ FS $\$$ Gy } & \multicolumn{3}{c|}{ Gy } \\
\cline { 2 - 7 } & ADF & t & k & ADF & t & k \\
\hline Hong Kong & $14.8236^{* * *}$ & 0.0006 & 2 & 1.23012 & 0.3610 & 2 \\
\hline Macao & $15.0021^{*} * *$ & 0.0103 & 2 & 1.25134 & 0.3721 & 2 \\
\hline Pearl River Delta & $20.6016^{* * *}$ & 0.0018 & 4 & 1.6892 & 0.2832 & 4 \\
\hline China & $19.7261 * * *$ & 0.0008 & 4 & 1.66532 & 0.2606 & 4 \\
\hline
\end{tabular}

In terms of the relationship between economic growth and financial structure, all countries or regions show a one-way causal relationship, indicating that financial structure is the Granger cause of economic growth ("Table VII").

TABLE VII. GRANGER CAUSALITY TEST OF ECONOMIC STRUCTURE AND FINANCIAL STRUCTURE

\begin{tabular}{|l|l|l|l|l|l|l|}
\hline \multirow{2}{*}{ Regions } & \multicolumn{3}{|c|}{ ES $\$$ FS } & \multicolumn{3}{c|}{ FS ES } \\
\cline { 2 - 7 } & \multicolumn{1}{|c|}{ F } & p & k & F & p & k \\
\hline Hong Kong & $6.26120^{* *}$ & 0.0260 & 1 & 0.00076 & 0.9812 & 1 \\
\hline Macao & $6.56312^{* *}$ & 0.0321 & 1 & 0.00106 & 0.9926 & 1 \\
\hline Pearl River Delta & 1.95180 & 0.3461 & 2 & 0.21346 & 0.8964 & 2 \\
\hline China & 1.49562 & 0.2645 & 2 & 0.18023 & 0.8621 & 2 \\
\hline
\end{tabular}

a. Note: Note: $\&$ and $\%$ represent significant levels of $1 \%, 5 \%$ and $10 \%$, respectively.

\section{Model comparison of the "threshold effect" of the dual-wheel driving of economic structure and financial structure}

There is relatively large heterogeneity between the four economies in terms of the interrelationship between economic structure, financial structure and economic growth. And especially in the relationship between economic structure and financial structure, the high income of Hong Kong, Macao has at least one significant causal relationship between, but in comparison, in China and the Pearl River Delta with low income, the dual-wheel driving can also promote economic growth. In the process of economic structural adjustment and financial structure optimization, broken points emerge in the coupling relationship, that is, the mismatch of supply and demand of synergetic chain, which leads to the source of economic growth in China and the pearl river delta — "single-wheel driving".

The model comparison of the "threshold effect" of the dual-wheel driving of economic structure and financial structure is shown in "Table VIII".

TABLE VIII. MODEL COMPARISON OF THE "THRESHOLD EFFECT" OF THE DUAL-WHEEL DRIVING OF ECONOMIC STRUCTURE AND FINANCIAL STRUCTURE

\begin{tabular}{|c|c|c|c|c|c|}
\hline Regions & $\begin{array}{c}\text { Per capita } \\
\text { income } \\
(U S \$)\end{array}$ & $\begin{array}{c}\text { The } \\
\text { transformation of } \\
\text { economic structure } \\
\text { drives economic } \\
\text { growth } \\
\end{array}$ & $\begin{array}{l}\text { The optimization of } \\
\text { financial structure } \\
\text { promotes economic } \\
\quad \text { growth }\end{array}$ & $\begin{array}{l}\text { The coupling } \\
\text { of economic } \\
\text { structure and } \\
\text { financial } \\
\text { structure } \\
\end{array}$ & Driving model \\
\hline Macao & 71875 & Yes & Yes & Yes & Dual-wheel driving \\
\hline Hong Kong & 48815 & Yes & Yes & Yes & Dual-wheel driving \\
\hline Pearl River Delta & 16177 & No & Yes & No & Single-wheel driving \\
\hline China & 10510 & No & Yes & No & Single-wheel driving \\
\hline
\end{tabular}

\section{CONCLUSION}

In conclusion, based on the panel data of 11 cities in the Guangdong-Hong Kong-Macao Greater Bay Area from 1997 to 2017, this paper applies the empirical methods of FMOLS and Granger to analyze the dynamic relationship between the "dual-wheel driving" of economic growth in the Greater Bay Area. It is concluded that the "dual-wheel" synergy of economic growth in different regions promotes high-quality economic development; on the contrary, "dual-wheel" 
dislocation inhibits high-quality economic development, showing a single-wheel driving effect.

Through the analysis of different economic entities in the Greater Bay Area, especially the study of highincome groups taking Hong Kong and Macao SAR as reference, it provides beneficial practical experience and enlightenment for the sustainable, stable and highquality economic development of the Guangdong-Hong Kong-Macao Greater Bay Area in the new era. First of all, from the perspective of economic structure transformation and financial structure optimization of the Guangdong-Hong Kong-Macao Greater Bay Area, it is the primary factor for the economic growth of the Greater Bay Area to build an effective mechanism of complementary advantages and synergetically coupled development, improve the coupling density of financial structure and economic structure, and amplify the "dual-wheel driving" effect of economic growth. Secondly, from the perspective of financial structure, based on the supply-side reform of financial structure, optimizing financial structure, deepening financial market, vigorously developing science and technology finance and activating financial vitality are the longterm ways to promote high-quality economic growth in the Greater Bay Area. Third, from the perspective of industrial restructuring, efforts should be made to promote the upgrading and transformation of industrial structure and improve the main service system of the tertiary industry (such as finance and producer services).

\section{References}

[1] Han Tingchun. Financial Development and Economic Development: Empirical Model and Policy Analysis [J]. The Journal of World Economy, 2001, (6): 35-40. (in Chinese)

[2] Tan Nuoyong. Empirical Research on the Relationship Between Financial Development and Economic Growth in China [J]. Economic Research Journal, 1999, (10): 53-61. (in Chinese)

[3] Mi Jianguo, Li Jianwei. Theoretical Thinking and Empirical Analysis on the Relationship Between China's Financial Development and Economic Growth [J]. Management World, 2002, (4): 51-56. (in Chinese)

[4] Wang Shuhua, Yang Youzhen. Supply-leading Financial Development and Economic Growth: Theoretical Hypothesis and Empirical Facts [J]. Journal of Shanxi Finance and Economics University, 2011, (3): 41-47. (in Chinese)

[5] Dong Yingying, Liao Kegui. Empirical Study on the Relationship Between Financial Structure and Macroeconomic Structure in China [J]. Statistics \& Decision, 2013, (6): 159-161. (in Chinese)

[6] Fang Haowen. Empirical Study on the Relationship Between Financial Structure, Economic Structure and Consumption Volatility: Based on the View of China's Financial Constraints [J]. Journal of Tianjin University (Social Sciences), 2013, (3): 204-209 (in Chinese)

[7] Mao Dingxiang. Empirical Study on the Relationship Between Financial Structure and Industrial Structure in China [J]. Operations Research and Management Science, 2006, (05): 122127. (in Chinese)
[8] Rajan, Zingales. Financial Development and Growth [J]. American Economic Review, 1998, (88): 559-586.

[9] Greenwood J, Jovanovich B. Financial development and economic development $[\mathrm{J}]$. Economic Development and Cultural Change, 1990, (15): 257268.

[10] Goldsmith R W. Financial Structure and Development [M]. New Haven, CT: Yale University Press, 1969. 21-35. 